\title{
Systematic review of meta-analyses to assess the impacts of farming practices - A methodological framework
}

\author{
Makowski D. ${ }^{1}$, Bosco S. ${ }^{2}$, Chen M. ${ }^{3}$, Montero-Castaño A. ${ }^{2}$, Pérez-Soba M. ${ }^{2}$, Schievano A. ${ }^{2}$, Terres J-M. ${ }^{2}$ \\ INRAE, AgroParisTech, Université Paris-Saclay, UMR 518, 16 rue Claude Bernard 75231 Paris, France \\ Joint Research Center, Ispra, Italy \\ Université de Paris, Inserm U1153, CRESS, Epidemiology of Ageing and Neurodegenerative diseases, Paris, France
}

\begin{abstract}
Identifying sustainable agricultural practices to support policy development requires a rigorous synthesis of scientific evidence based on experiments carried out around the world. In agricultural science, meta-analyses (MAs) are now commonly used to assess the impact of farming practices on a variety of outcomes, including crop and livestock productions, biodiversity, greenhouse gas emissions, nitrate leaching, soil organic carbon, based on a large number of experimental data. MA has become a gold standard method for quantitative research synthesis, and the growing number of MAs available can potentially be used to inform decisions of policy makers. However, published MAs are heterogeneous both in content and quality, and a framework is needed to help scientists to report the results and quality levels of MAs in a rigorous and transparent manner. Such a framework must be implementable quickly - within weeks - to be operational and compatible with the time constraints of modern policymaking processes. In this paper, we propose a methodological framework for assessing the impacts of farming practices based on a systematic review of published MAs. The framework includes four main steps: (1) literature search of existing MAs, (2) screening and selection of MAs, (3) data extraction and quality assessment, and (4) reporting. Three types of reports are generated from the extracted data: individual reports summarizing the contents of each MA (MA summary reports), reports summarizing each of the impacts of a given farming practice on a specific environmental, climate mitigation, or production outcome (single-impact reports), and report summarizing all the impacts of a given farming practice on all the outcomes considered (general report). All these reports present the quality levels of the MAs examined on the basis of 16 quality criteria. The proposed framework is semi-automatic in the sense that the skeletons of the reports are generated automatically from the spreadsheet used for the data extraction and quality assessment. This semi-automatic procedure allows scientific experts to reduce the time needed in the reporting step. Since 2020, the proposed framework was successfully applied by a group of scientific experts to support decisions of EU policy makers, and examine a large diversity of single farming practices (e.g. nitrification inhibitors, biochar, liming) and cropping systems (e.g. organic systems, agroforestry) in a relatively short period of time. It provides an operational tool for scientists who want to supply policymakers with scientific evidence based on large numbers of experiments, in a timely and reproducible manner.
\end{abstract}

Keywords: Agricultural policy, Climate, Environmental impact, Evidence-based decision making, Farming practice, Meta-analysis, Systematic review. 


\section{Introduction}

The European Commission's Green Deal (COM, 2019) provides an action plan with clear goals for food system to be safe, nutritious and meet high environmental production standards. Indeed, the EU's "Farm to Fork Strategy" and the post 2020 Common Agricultural Policy (CAP) clearly aim to reduce environmental and climate impacts of agriculture, while increasing biodiversity and ecosystem services. Member States will implement the future CAP at national level through strategic plans outlining targeted interventions responding to their specific needs and producing tangible results to achieve EU objectives, while contributing to the Green Deal. The European Commission is responsible for evaluating and validating the CAP plans proposed by the Member States. Therefore, it is necessary to identify agricultural practices that effectively reduce air, soil and water pollution, reduce greenhouse gas emissions and increase biodiversity and pollination, and thus contribute to the environmental and climate objectives of the EU. The identification of sustainable practices requires robust scientific evidence emerging from experiments and observations carried out around the world. However, the wealth of data available makes communication to policy makers challenging. Hence, systematic and unbiased synthesis of available experimental data has become both a major scientific challenge and an essential step to foster evidence-based decision making (Minx et al., 2017).

Systematic review and meta-analysis (MA) are essential tools for the synthesis of knowledge in many fields, particularly in medical sciences but also in ecology and environmental sciences (Gurevitch et al., 2018). A systematic review involves the exhaustive assembly, evaluation and synthesis of all relevant studies dealing with a specific question. It is based on a detailed protocol limiting the bias and favoring a transparent and reproducible approach (Chalmers et al., 2002). Meta-analysis combines systematic review and statistical analysis and aims to provide quantitative information from a set of relevant primary studies. In agricultural science, it has been recognized that MA has several advantages over the use of single studies (Philibert et al., 2012; Makowski et al., 2019): i) MA increases the accuracy of the estimates of key outcomes (e.g. yield gains or changes in environmental impacts); ii) MA allows to assess the level of generality of local experimental results; iii) MA helps to analyze the variability of the performances of farming practices across a range of biogeographical, environmental and farm management conditions; and iv) MA helps to resolve seemingly contradictory research outcomes.

Numerous MAs have been published since the 2010s to quantify the impacts of a large range of farming practices and farming systems, such as cover crops, intercropping, agroforestry, organic farming and conservation agriculture, on many outcomes related to crop production, water and soil quality, biodiversity, pest- and disease-control, and greenhouse gas emissions (Beillouin et al., 2019; Makowski, 2019, 2021; Philibert et al., 2012; Tamburini et al., 2020; Su et al., 2021ab). For example, more than $10 \mathrm{MAs}$ (each including several dozen studies) have been conducted to evaluate the impact of agroforestry on soil organic carbon compared to arable systems without trees (e.g. Kim et al., 2016; Kuyah et al., 2019). However, published MAs are heterogeneous both in content and quality. Frequently, MAs published on a given topic do not show the same quality level, because some MAs were carried out according to strict rules, while others were conducted following less rigorous approaches. There is thus a need for a framework that not only summarises the results of the available MAs in a systematic way, but also presents their quality level in a transparent manner. The framework needs to be implemented rapidly - in few weeks for a given topic - to be operational and compatible with the time constraints of modern policy making processes.

In this paper, we present a framework to report on the impacts of given farming practices based on a systematic review of MAs, as recently done in medical science (Aromataris et al., 2015; Ingoe et al., 2019). The proposed methodological framework provides an operational tool for scientists who want to supply policymakers with low-bias scientific evidence based on large numbers of experiments, in a 
timely manner. The focus of this paper is on the impacts of farming practices on key outcomes related to agricultural production, environment and climate change mitigation. However, the framework is generic and can be used to address other outcomes of interest, related to e.g. crop characteristics, crop quality, human health, or socio-economic impacts such as farmers' income. The main steps of the framework and the conclusions are presented in the next sections.

\section{Overview of the framework}

The objective of the framework is to synthetize all existing (or at least the largest possible number of) MAs assessing the environmental and climate impacts of a given farming practice. As a reminder, a MA aims at estimating a mean effect size from a group of individual experiments (Figure 1). In agricultural sciences, an effect size measures the effect of an intervention (a farming practice of interest) relatively to a comparator (a practice used as a benchmark or an absence of intervention) on an outcome of interest in a range of soil, climate, and farming conditions. For example, if the practice considered is "biochar application" and the outcome is "soil organic carbon", the effect size will measure the effect of biochar (intervention) compared to no biochar application (comparator) on soil organic carbon (outcome). Various types of effect size can be considered but, typically, the effect size is often the logarithm of the outcome in the treatment to the comparator (e.g. the logarithm of the ratio of soil organic carbon with biochar amendment to soil organic carbon without biochar amendment).

Figure 1. Illustration of the basic principle of a meta-analysis. Each experiment reports observations collected in a comparator and an intervention (noted $Y_{C}$ and $Y_{l}$, respectively). Individual effect sizes (typically, the logarithm of $Y_{l} Y_{C}$ ) are computed from these observations for each experiment. Finally, a mean effect size (and its confidence interval, usually at a level of $95 \%$ ) is computed from the set of individual effect sizes. In the example presented, the mean effect size is significantly positive because its confidence interval (horizontal red bar) does not include zero.

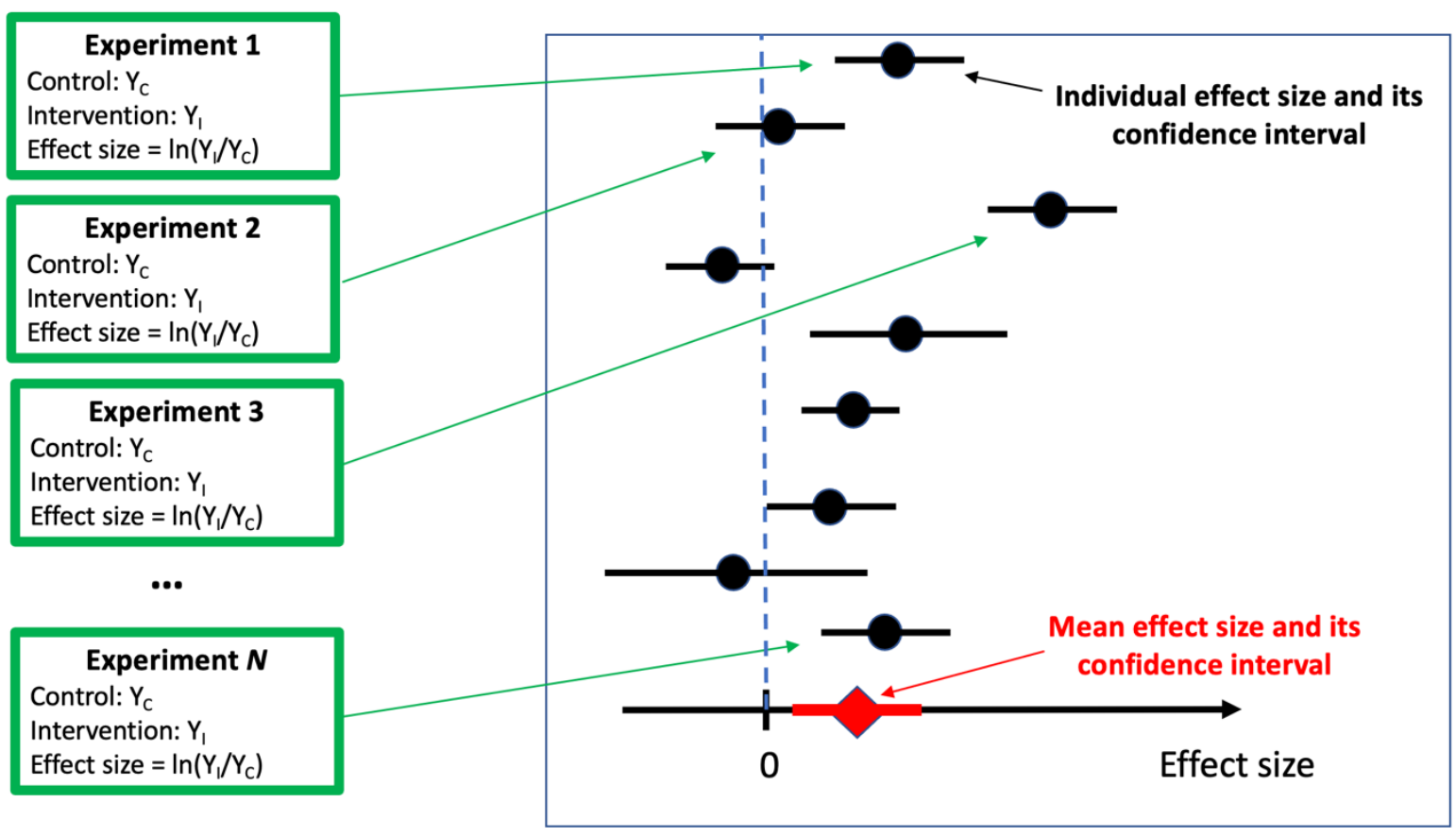

As shown in Figure 1, each individual experiment reports an individual effect size and its associated confidence interval, and the set of individual effects is then used to estimate a mean effect size (and its own confidence interval) using an appropriate statistical method, often based on a random-effect model. In addition to mean effect size estimates, some MAs also report results for various subgroups 
of experiments corresponding to different environmental conditions and identify influential factors (e.g. geographical areas, soil types) (Gurevitch et al., 2018; Makowski et al., 2019).

The main objective of the proposed framework is to retrieve and summarize the largest possible number of MAs published on a given farming practice. It can be applied to any farming practice whether it is a very specific single practice - buffer strips along water courses -, or a whole system of agricultural practices - organic farming or agroforestry -. These farming practices can be defined in different ways but, in our case, the list of farming practices was provided by the European Commission Directorate General Agriculture and Rural Development (DG AGRI).

For each farming practice considered, the framework is implemented in four steps, briefly explained in Figure 2 (details are given step by step in the next sections). Step 1 is a systematic search of the published MAs assessing one or several different impacts of the farming practice under consideration, and produces a list of references. Step 2 is a selection of relevant MAs based on explicit criteria from the list of references obtained at step 1. At step 3, the main characteristics of the MAs, their results and their conclusions are extracted and stored in a dedicated spreadsheet (see Appendix 1). Finally, at step 4, three types of reports are generated per farming practice from the data extracted at step 3: (i) Individual reports (one report per MA and per impact), (ii) Single-impact reports (one report per impact), (iii) General report (one per farming practice).

Figure 2. The four main steps of the framework for performing a systematic review of meta-analyses (MAs) and their associated products. The four steps are separately applied for each farming practice of interest. The end product consists of three types of reports: individual reports summarizing the content of each single MA for each impact, single-impact reports summarizing the main conclusions of the whole group of MAs focusing on the same impact (e.g. all MAs assessing the impact of the considered farming practice on greenhouse gas emission), and a general report providing a summary of all MAs and all impacts for the farming practice considered.

\section{Steps}

Step 1. Systematic search of MAs

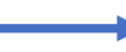

List of references

Step 2. Screening and selection

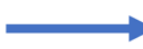

List of selected MAs

Step 3. Data extraction and quality assessment of MAs

Step 4. Reporting

\section{Results}




\section{Procedure implemented at each step}

\section{Step 1. Systematic search of published MAs}

MAs are retrieved using a systematic literature search based on the use of a search equation (see examples of search equations in Table 1). One specific search equation needs to be defined for each farming practice. The first part of the search equation includes keywords related to the targeted agricultural practice, taking care to include as many synonyms as possible. The second part is used to restrict the search to papers dealing with topics specifically related to farming practices. This second part is not always necessary, but it can be useful when the keywords listed in the first part of the search equation leads to a selection with a high number of irrelevant papers. The third part of the search equation includes one or several specific keywords to focus the search only on meta-analysis or systematic review, excluding individual studies. Although our framework is mainly intended to synthetize MAs, we also consider systematic reviews without formal statistical analysis if they include some quantitative results. Unsystematic reviews are excluded.

It is not recommended to include keywords related to one or several specific outcomes, unless the scope of the assessment was explicitly restricted to one or few specific outcomes. As it is difficult to know beforehand precisely all outcomes studied in the literature, we suggest the use of a relatively general search equation to retrieve the highest number of MAs on all outcomes. We also recommend to use, if possible, at least two scientific databases such as Web of Science and Scopus to implement the search equation. A single list of references is produced from the various databases by removing duplicates. It can also be relevant to add unpublished MAs made available by research projects or by organizations dedicated to research synthesis. Additional relevant MAs may be found in the reference lists of retrieved papers as well.

Table 1 - Structure of the search equation and examples.

\begin{tabular}{|c|c|c|c|c|c|}
\hline $\begin{array}{l}\text { Farming } \\
\text { practice }\end{array}$ & $\begin{array}{l}\text { Keywords related to the } \\
\text { practice }\end{array}$ & & $\begin{array}{l}\text { Keywords used to } \\
\text { focus the search on } \\
\text { agriculture* }\end{array}$ & & $\begin{array}{l}\text { Keywords used to select MAs and } \\
\text { systematic reviews }\end{array}$ \\
\hline Organic farming & $\begin{array}{l}\text { TOPIC: ("organic farm*" OR } \\
\text { "organic agriculture" OR } \\
\text { "organic system*" OR } \\
\text { "organic product*") }\end{array}$ & & & AND & $\begin{array}{l}\text { TOPIC: ("meta-analy*" OR "systematic* } \\
\text { review*" OR "evidence map" OR } \\
\text { "global synthesis" OR "evidence } \\
\text { synthesis" OR "research synthesis") }\end{array}$ \\
\hline $\begin{array}{l}\text { Nitrification } \\
\text { inhibitors }\end{array}$ & $\begin{array}{l}\text { TOPIC: ("nitr* inhibit*" OR } \\
\text { "controlled-release fert*" } \\
\text { OR "urease inhibit*" OR } \\
\text { "enhanced-efficiency fert*") }\end{array}$ & & & AND & $\begin{array}{l}\text { TOPIC: ("meta-analy*" OR "systematic* } \\
\text { review*" OR "evidence map" OR } \\
\text { "global synthesis" OR "evidence } \\
\text { synthesis" OR "research synthesis") }\end{array}$ \\
\hline Biochar & $\begin{array}{l}\text { TOPIC: (biochar OR charcoal } \\
\text { OR "black carbon") }\end{array}$ & AND & $\begin{array}{l}\text { TOPIC: (soil* OR } \\
\text { agricultur* OR farm*) }\end{array}$ & AND & $\begin{array}{l}\text { TOPIC: ("meta-analy*" OR "systematic* } \\
\text { review*" OR "evidence map" OR } \\
\text { "global synthesis" OR "evidence } \\
\text { synthesis" OR "research synthesis") }\end{array}$ \\
\hline
\end{tabular}

\footnotetext{
* Not always used. It is only used to restrict the search when a high number of papers not related to agricultural activities is retrieved.
} 


\section{Step 2. Screening and selection of MAs}

The first screening of the studies retrieved at step 1 is based on titles and abstracts. Criteria for inclusion/exclusion are defined before the screening. At least, three main criteria lead to the exclusion of a study: (1) the study does not deal with the considered farming practice; (2) the study does not assess the impact of the farming practice on any of the outcomes of interest, i.e., environmental impacts or crop yield compared to a control; (3) the study is neither a MA nor a systematic review. In case or doubt and whenever possible, a second reader is requested to validate the screening results in order to confirm the relevance of the selection. At the end of the screening, MAs are classified into three categories: (i) excluded, (ii) excluded but potentially relevant for another farming practice of interest to the decision makers, (iii) potentially relevant for the farming practice considered. A second screening is done based on the full texts of all MAs classified as potentially relevant (i.e. MAs of type iii defined above). During the second screening, MAs are read in detail, and several MAs are discarded again at this stage if they do not fulfill the selection criteria.

\section{Step 3. Data extraction and quality assessment of MAs}

Main characteristics and results of the selected MAs are extracted from the articles. The extracted items are related to:

- References (authors, titles, DOI, etc.)

- Objectives of the MAs

- Methods implemented in the MAs (search strategy, data analysis etc.)

- Main characteristics of the experiments (intervention, comparator, population, impact, metric, effect size etc.)

- Main results and influential factors (soil characteristics, climate variables etc.)

- Knowledge gaps

Appendix 1 presents the full list of extracted items. These descriptors are reported in the different columns of a spreadsheet used to store the data. In this spreadsheet, separate rows are used to describe the characteristics of different MAs and of different impacts. Impacts are defined from the results found in the selected MAs (e.g., biodiversity, soil organic carbon, greenhouse gas emissions, soil quality, crop yields). All data and texts reported in the spreadsheet are extracted from the text of the MAs, sticking as much as possible to the original wording of the authors.

In addition to the items listed above, each farming practice impact is rated based on the mean effect size estimates reported in the MAs. For each MA and each impact, ratings are chosen among four possible levels (positive, negative, no effect, uncertain) depending on the mean effect size estimates (in particular, its positive or negative direction), their statistical significances, and the reliability of the MA. When necessary, several ratings are specified for different comparators or interventions.

Finally, each MA is assessed using 16 quality criteria covering different aspects of the MAs (Figure 3 ). These criteria cover all the different steps followed when conducting a MA: Scoping (definition of the objective of the MA), Search (search of potentially relevant individual published studies), Study selection (selection of the relevant individual studies), Data extraction (extraction of the experimental data useful for computing the effect sizes), Statistical analysis (analysis of the data to estimate the mean effect size and analyze between-study variability), Bias and uncertainty (analysis of the uncertainty of the results and analysis of the risk of bias). When a criterion is satisfied, a value of 1 is reported in the corresponding column of the spreadsheet, and a zero is reported otherwise. We selected the quality criteria from those listed in Beillouin et al (2019). Several of these criteria can also be found in Aromaratis et al. (2015) and Nakagawa et al. (2017). 
Figure 3. Quality criteria used to assess the quality of the selected MAs. The quality criteria cover the main steps followed when performing a MA.

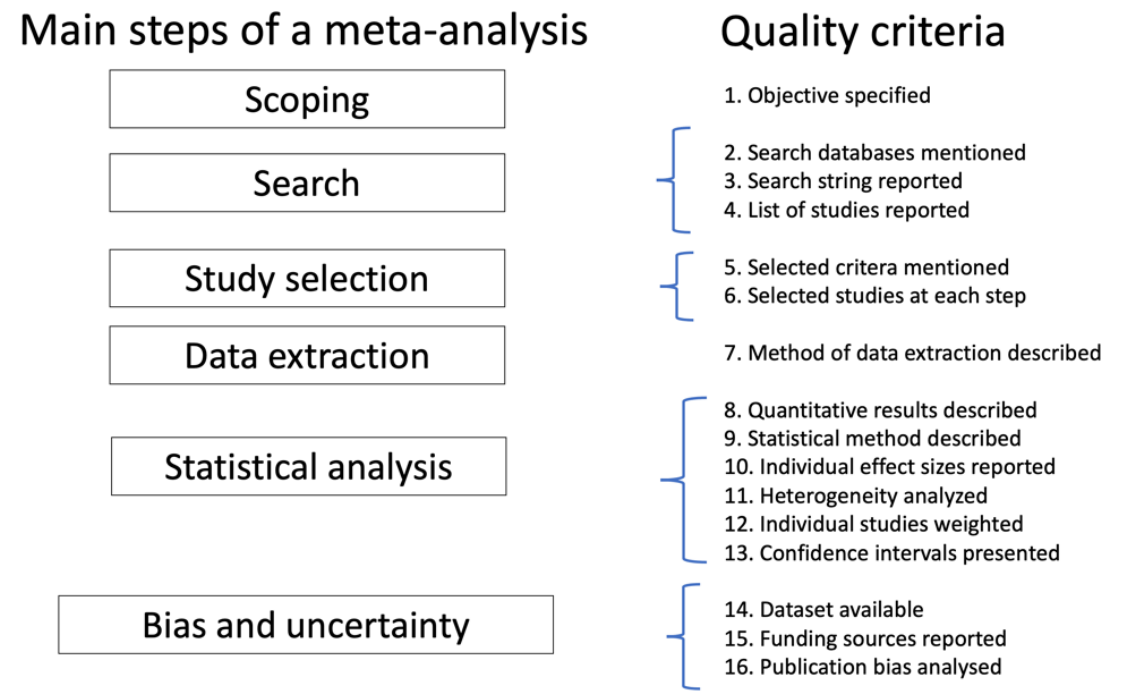

\section{Step 4. Reporting}

In order to provide policy-makers with detailed information but also with synthetic results, we generate three types of reports including different types of information:

- Individual reports summarizing the main characteristics of each MA, including their main findings and level of quality, and their conclusions;

- Single-impact reports summarizing the results for each impact, separately. Each report presents a summary table dedicated to each single impact, outlining the main results of all MAs reporting on the impact considered;

- A general report summarising all impacts of the considered farming practice across all selected MAs.

The first type of report describes the main characteristics of each MA with a relatively high level of detail. It includes the objective of the MA, the protocol used to conduct the MA, and the main results (including quantitative results). The second type of reports presents an intermediate level of detail and summarizes the main results of all MAs for each single impact and thus provide an overview of the evidence available on the effect of the considered farming practice on each impact. Finally, the third type of report provides the highest synthesis level, with an overview of all impacts associated with one specific farming practice. Each one of these reports is short and includes no more than a few pages. Examples are shown in Appendices 2, 3, and 4 for one farming practice (Nitrification inhibitor application).

An original feature of our framework is that it relies on "R markdown" (Figure 4) to generate reproducible documents with $R$ ( $R$ markdown reference guide, 2014; $R$ Core Team 2021). Specific $R$ scripts were written to generate the three types of reports listed above with this software. These scripts allow us to adjust quickly the contents of the reports to any modification made in the spreadsheet built at step 3 . As the spreadsheet is updated several times during the extraction process in step 3 (e.g. to add a new MA or to make corrections in the spreadsheet contents), it is important to be able to quickly adjust the reports to any change made in the spreadsheet. It would be tedious to do it manually and this would increase a lot the risk of mistakes and of wrong reporting. Based on this approach, individual reports are generated automatically from the spreadsheet produced at step 3 using R markdown, without the need of any manual adjustment. The 
approach is slightly different for the other two types of reports. Indeed, as single-impact reports and general reports require some manual fine-tuning, these two types of report are generated in three stages; first, report skeletons are produced automatically using R markdown, second, the report contents are fine-tuned manually in order to finalize the texts and the tables and, third, the final versions of the reports are produced after two rounds of review done by external readers (Figure 4).

Figure 4. Procedure implemented to generate the reports using $\mathrm{R}$ markdown scripts from the spreadsheet including the main descriptors and results of the selected meta-analyses. This procedure is implemented for each farming practice separately.

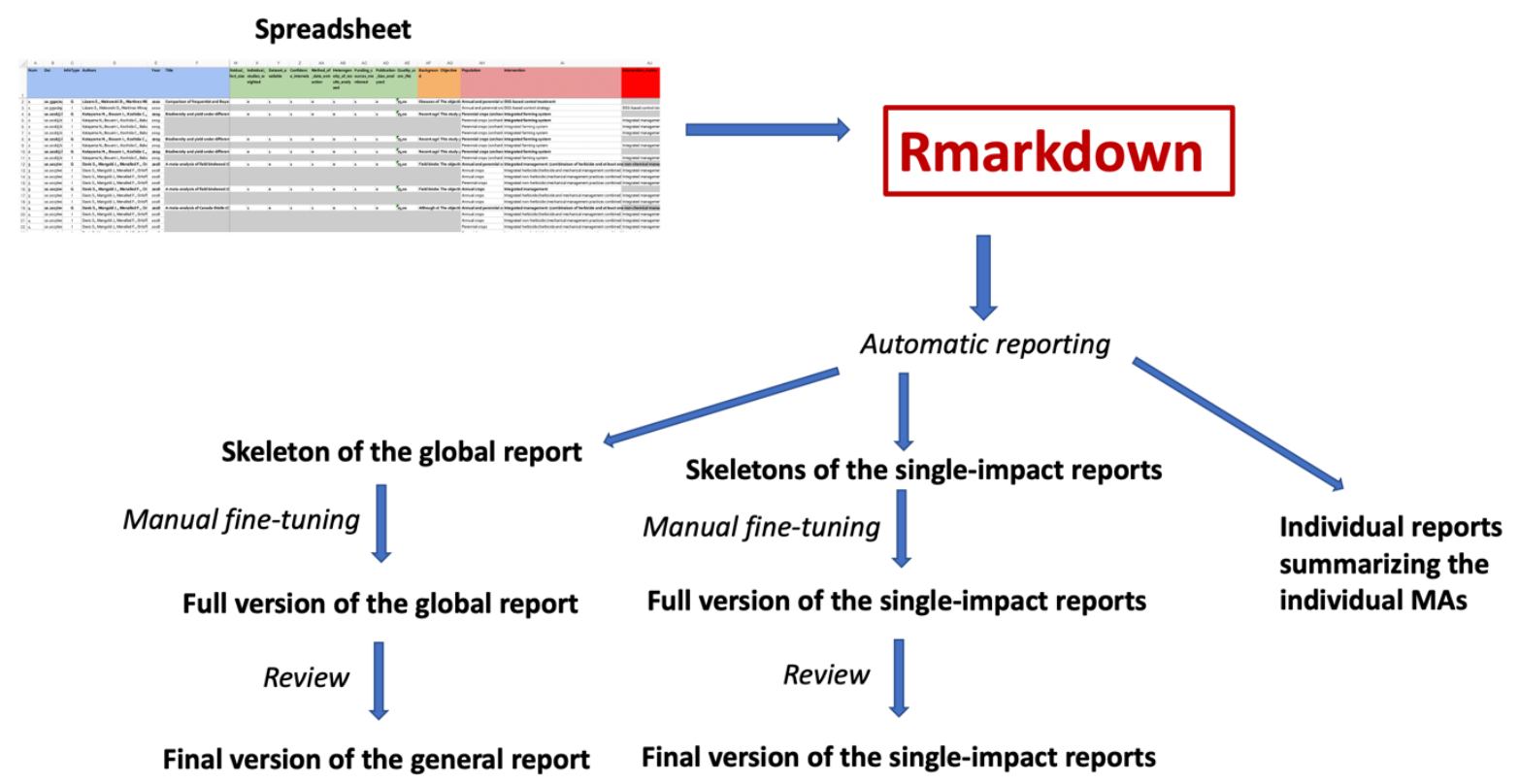

One of the key elements of the general report consists in a synopsis matrix scoring the considered farming practice for all impacts based on the whole set of MAs. An example of this matrix is shown in Figure 5 for the farming practice "Nitrification inhibitor application" based on 16 MAs, each including between 4 and 376 individual experimental studies (the 16 MAs are listed in Appendix 3 section 7). The rows of the matrix correspond to the different impacts and the columns include the number of MAs showing "positive", "negative", "no effect", or "uncertain" impacts according to the results included in the spreadsheets produced at step 3. The counting is done in two different ways, first considering all MAs, and then considering a restricted set of MAs with acceptable quality levels (here, at least $50 \%$ of the quality criteria satisfied), in order to assess the robustness of the conclusions. Each cell of the matrix thus reports two numbers. The first number corresponds to the number of MA reporting positive, negative, no effect or uncertain effect for the impact considered among the whole set of MAs selected at step 2, while the second number (between brackets) indicates the number of MA with a quality level higher than $50 \%$ reporting the same effects (Figure 5 ). When all MAs reporting the effect specified have a quality level higher than $50 \%$, the two numbers are equal. Figure 5 shows that nitrification inhibitor application had contrasting effects depending on the impacts considered. For example, according to the majority of the MAs considered, nitrification inhibitor applications were able to decrease $\mathrm{N}_{2} \mathrm{O}$ emissions (9 MAs out of 10 showed a positive effect) but were not able to decrease $\mathrm{NH}_{3}$ air pollutant emissions ( 5 MAs reported negative effects, an increase of emission levels; 5 MAs reported no effect; and 1 MA was uncertain due to unconclusive results), compared to comparators without nitrification inhibitor application. 
Figure 5. Example of synopsis matrix. This matrix scores the impacts of the farming practice "Nitrification inhibitor application" (intervention) vs "No application" (comparator). This matrix was produced from 16 published metaanalyses assessing the impacts of nitrification inhibitor application on crop yield and several other outcomes. Each number indicates how many meta-analyses report positive, negative, no effect, or uncertain effect. For each impact, the effect with the higher score is marked in bold and the cell colored (in green, red, yellow, or grey for positive, negative, no effect, and uncertain effect, respectively). The numbers between parentheses indicate the number of MAs with a quality score higher than or equal to $50 \%$. Here, out of 16 MAs, 6 included studies conducted in Europe and 14 have a quality score higher than $50 \%$. Some MAs reported more than one impact.

\begin{tabular}{|c|c|c|c|c|c|}
\hline \multicolumn{2}{|l|}{ Impact } & Positive & Negative & No effect & Uncertain \\
\hline \multirow[t]{2}{*}{ Decrease of air pollutants emission } & $\mathrm{NH}_{3}$ & o & $5(5)$ & $5(5)$ & $1(0)$ \\
\hline & NO & $3(3)$ & o & $1(1)$ & o \\
\hline \multirow[t]{3}{*}{ Decrease of GHG emission } & $\mathrm{N}_{2} \mathrm{O}$ & $9(8)$ & o & o & $1(0)$ \\
\hline & $\mathrm{CH}_{4}$ & $1(1)$ & o & $2(2)$ & o \\
\hline & $\mathrm{CO}_{2}$ & $1(1)$ & o & $1(1)$ & o \\
\hline \multicolumn{2}{|l|}{$\begin{array}{l}\text { Decrease of } \mathrm{N} \text { leaching or run-off } \\
\left(\mathrm{NO}_{3-}, \mathrm{NH}_{4+}, \mathrm{DIN} *\right)\end{array}$} & $4(4)$ & $2(2)$ & $1(1)$ & o \\
\hline \multicolumn{2}{|l|}{ Increase plant $\mathrm{N}$-uptake } & $5(5)$ & $\circ$ & $4(4)$ & o \\
\hline \multirow[t]{3}{*}{ Increase soil content of fertilizer-derived $\mathrm{N}$ forms } & $\mathrm{NH}_{4}^{+}$ & $2(2)$ & o & 0 & o \\
\hline & $\mathrm{NO}_{3}$ & o & $2(2)$ & 0 & o \\
\hline & $\begin{array}{l}\text { All N- } \\
\text { forms* }\end{array}$ & $1(1)$ & o & $2(2)$ & o \\
\hline \multicolumn{2}{|l|}{ Increase yield } & $6(6)$ & 0 & $3(3)$ & o \\
\hline
\end{tabular}

* All nitrogen ( $\mathrm{N})$ forms include dissolved inorganic nitrogen forms $\left(\mathrm{NH}_{4}+, \mathrm{NO}_{3-}, \mathrm{NO}_{2}-\right)$ and organic $\mathrm{N}$.

\section{Discussion}

The framework described in this paper shares several similarities with other approaches developed recently in the field of medical science for conducting an umbrella review of systematic reviews. As in Smith et al. (2011) and Ingoe et al. (2019), our methodological framework starts with a systematic search of the literature and the use of explicit selection criteria to identify relevant studies. Moreover, as in Smith et al. (2011) and Aromataris et al. (2015), our framework uses standardized tools to extract the information and includes a quality assessment of all selected meta-analyses using several quality criteria.

However, our approach shows several major differences compared to these methods. First, contrary to the above-mentioned references, our approach gives a stronger focus to MAs than to qualitative systematic reviews. The reason is that our main objective is to determine whether agricultural practices have a significant effect on the impacts under consideration, including the level of uncertainty behind the assessment. In this way, we can provide decision-makers with robust information about the performances of the assessed farming practices. Note, however, that systematic reviews reporting some quantitative results are not excluded, even if no formal statistical analysis was conducted. They can be considered as well and included in our analysis, but they will typically get lower scores for the quality criteria related to the statistical analysis and are often rated as uncertain in our reports. 
A second difference lies in the quality criteria considered in the framework presented in this paper, which are more numerous and broader in scope than those used in the above methods. They assess three main characteristics of the MAs selected: the quality of the literature review and studies selection, the quality of the statistical analysis, and the quality of the risk of bias analysis.

Third, several of the items extracted from the reviewed MAs are specific to our field of application impact of farming practices - and differ from those considered in the field of medical sciences. In particular, our framework is designed to deal with a multicriteria analysis because farming practices need to be assessed considering a large range of impacts and potential trade-offs, related to environmental, climate and production outcomes, such as soil carbon content, greenhouse gas emissions, soil erosion, crop yield etc. The structures of the spreadsheet used to store the results and of the reports generated from this spreadsheet are thus designed to handle several impacts. They are also designed to deal with multiple comparators (i.e., different cropping systems or practices used as controls in experiments) and to report major factors related to environmental conditions or management practices (e.g., soil characteristics, climate conditions, crop species) influencing the direction and strength of the impact considered.

Finally, the reports produced by our framework are easily reproducible because they rely on a dynamic document producing system based on R notebooks. This ensures a good traceability of the results, and allows scientific evidence on the environmental impacts of agricultural practices to be presented in a way that is synthetic, transparent and easily accessible to policy makers. The results of our framework can also be used to identify research gaps, in particular identify environmental impacts that have not yet been covered by any meta-analysis.

Despite its merits, our approach has several limitations. Although generally quick to implement, data extraction in step 3 can be labour intensive when the number of available meta-analyses on the farming practice under consideration is high. As long as the number of MAs remains below 15 or 20, the whole process can be done in a few days. But for some topics, the number of available MAs can reach 100 or more. It may then be necessary to spend several weeks extracting data before generating reports and sending them to decision-makers, which can slow down the decision-making process. However, this type of situation is not very frequent and, even when it occurs, the proposed approach is much less time-consuming than performing a new MA. Another limitation of the proposed approach is that the results of the MAs are not combined together, as in a second-order MA where the mean effect sizes of the different MAs are re-analysed to produce a single overall mean effect size. In our approach, the results of the MAs are presented independently, without being aggregated. However, we believe that a presentation of the results of individual MAs is more informative without aggregation than with because it allows experts to report on the strengths and weaknesses of each MA and also to describe the heterogeneity of the results according to the conditions under which the MAs were conducted. This approach therefore limits the risk of drawing overly simplistic conclusions about the performance of different agricultural practices and, on the contrary, makes it possible to describe the variability of impacts associated with the innovative agricultural practices put forward to improve the sustainability of agriculture.

\section{References}

Aromataris E., Fernadez R., Godfrey C. M., Holly C., Khalil H., Tungpunkom P. 2015. Summarizing systematic reviews: methodological development, conduct and reporting of an umbrella review approach. Int J Evid Based Healthc 13, 132-140.

Beillouin D., Ben-Ari T., Makowski D. 2019. Evidence map of crop diversification strategies at the global scale. Environmental Research Letters 14, 123001 
COM/2019/640 final Communication from the Commission to the European parliament, the European council, the council, the European economic and social committee and the Committee of the regions The European Green Deal.

Gurevitch J., Koricheva J., Nakagawa S., Stewart G. 2018. Meta-analysis and the science of research synthesis. Nature 555, 175-182

Kim D.G., Kirschbaum M.U., Beedy T.L. 2016 Carbon sequestration and net emissions of CH4 and N2O under agroforestry. Synthesizing available data and suggestions for future studies. Agriculture, Ecosystems \& Environment 226, 65-78.

Kuyah S., Whitney C.W., Jonsson M., Sileshi G.W., Oborn I., Muthuri C.W., Luedeling E. 2019 Agroforestry delivers a win-win solution for ecosystem services in sub-Saharan Africa. A meta-analysis. Agronomy for Sustainable Development 39, 47.

Ingoe H. M. A., Coleman E., Eardley W., Rangan A., Hewitt C., McDaid C. 2019. Systematic reviews of systematic reviews for effectiveness of internal fixation for flail chest and rib fractures in adults. BMJ Open 9, e023444.

Makowski D. 2019. $\mathrm{N}_{2} \mathrm{O}$ increasing faster than expected. Nature climate change 9, 909-910

Makowski D., Piraux F., Brun F. 2019. From Experimental Network to Meta-analysis Methods and Applications with R for Agronomic and Environmental Sciences. Springer.

Makowski D. 2021. Editorial of the special issue "Evidence synthesis in agronomy". European journal of Agronomy 121, 1261183

Minx J.C., Callaghan M., Lamb W.F, Garad J., Edenhofer O. 2017a. Learning about climate change solutions in the IPCC and beyond. Environmental Science and Policy 77, 252-259

Nakagawa S., Noble D.W.A., Alistair M. Senior, Malgorzata Lagisz. 2017. Meta-evaluation of meta-analysis: ten appraisal questions for biologists. BMC Biology 15, 18.

Philibert A., Loyce C., Makowski D. 2012. Assessment of the quality of meta-analysis in agronomy. Agriculture Ecosystems \& Environment 148, 72-82

R Core Team, 2021. R: A language and environment for statistical computing. R Foundation for Statistical Computing, Vienna, Austria. https://www.R-project.org/

R markdown reference guide. 2014. https://www.rstudio.com/wp-content/uploads/2015/03/rmarkdownreference.pdf? ga=2.3209648.1095315087.1619466723-1350586200.1619466723

Smith V., Devane D., Begley C.M., Clarke M. 2011. Methodology in conducting a systematic review of systematic reviews of healthcare interventions BMC Medical Research Methodology 11, 15.

Su Y., Gabrielle B., Beillouin D., Makowski D. 2021a. High probability of yield gain through conservation agriculture in dry regions for major staple crops. Scientific reports 11, 3344

Su Y., Gabrielle B., Makowski D. 2021b. The impact of climate change on the productivity of conservation agriculture. Nature climate change, in press.

Tamburini G., Bommarco R., Cherico Wanger T., Kremen C., van der Heijden M.G.A., Liebman M., Hallin S. 2020. Agricultural diversification promotes multiple ecosystem services without compromising yield. Science advances 6, eaba1715.

Tang L.L., Caudy M., Taxman F. 2013. A Statistical Method for Synthesizing Meta-Analyses. Comput Math Methods Med. 2013, 732989. 
Appendix 1: List of the descriptors of the spreadsheet reporting characteristics and main results of the MAs.

\begin{tabular}{|c|c|c|}
\hline Data extraction step & Column name & Definition \\
\hline \multirow[t]{5}{*}{ LITERATURE SEARCH } & Search equations WOS & Keywords search string used in WOS \\
\hline & Search equations SCOPUS & Keywords search string used in SCOPUS \\
\hline & Date of search & Date when literature search was conducted \\
\hline & Criteria for inclusion/exclusion & $\begin{array}{l}\text { List of the criteria used to include or exclude the MA } \\
\text { during screening or data extraction }\end{array}$ \\
\hline & Definitions of the farming practice & $\begin{array}{l}\text { Official/widely accepted definition of the FP and the } \\
\text { corresponding references }\end{array}$ \\
\hline \multirow[t]{21}{*}{ SCREENING } & Source_of_search & $\begin{array}{l}\text { Indicates whether the MA was found by the systematic } \\
\text { search process or comes from the search for other } \\
\text { farming practice. }\end{array}$ \\
\hline & Data_search & Date when literature search was conducted \\
\hline & DOI & Publication DOI \\
\hline & Authors & List of authors of the MA \\
\hline & Year & Publication year \\
\hline & Title & Publication title \\
\hline & Journal & Publication journal \\
\hline & Abstract & Publication abstract \\
\hline & Type & $\begin{array}{l}\text { Publication type (whether the paper is a MA, a non- } \\
\text { quantitative systematic review, a non-quantitative review } \\
\text { or a modelization study) }\end{array}$ \\
\hline & Cause_exclusion & $\begin{array}{l}\text { Reason for excluding the publication from the final } \\
\text { selection }\end{array}$ \\
\hline & Also_only_valid_for & $\begin{array}{l}\text { Indicates whether the publication is potentially useful for } \\
\text { other farming practices }\end{array}$ \\
\hline & Volume & Publication volume \\
\hline & Issue & Publication issue \\
\hline & Start_page & Start page of the publication \\
\hline & End_page & End page of the publication \\
\hline & Link & Link to publication \\
\hline & Comment & Any comment \\
\hline & Reviewer & Initials of the researcher conducting the review \\
\hline & & $\begin{array}{l}\text { Color code: red = exclusion based on titles and abstracts; } \\
\text { orange = exclusion after full text analysis; blue = selected } \\
M A ; \text { green = excluded but potentially useful for other } \\
\text { farming practice }\end{array}$ \\
\hline & Num & Identification number of the MA \\
\hline & Doi & Publication DOI \\
\hline
\end{tabular}




\begin{tabular}{|c|c|c|}
\hline \multirow[t]{13}{*}{$\begin{array}{l}\text { FULL TEXT ANALYSIS AND } \\
\text { EXTRACTED DATA: Study } \\
\text { general description }\end{array}$} & InfoType & $\begin{array}{l}\text { Indicates the type of information that is reported. } \\
\text { InfoType = "G" lines report publication general } \\
\text { information, quality rating and results regarding the effect } \\
\text { of the farming practice on the specific environmental } \\
\text { impact, while InfoType = "I" lines report results for a } \\
\text { specific combination of treatment-control-metric of an } \\
\text { impact. For one specific impact, the data extracted for } \\
\text { each MA is split between } 1 \text { line "G" and at least } 1 \text { line "I". } \\
\text { The number of "G" lines for one MA corresponds to the } \\
\text { number of impacts for which the MA report results } \\
\text { comparing the tested farming practice to a reference } \\
\text { farming practice. As an example, a MA can report results } \\
\text { for different metrics or several comparators for the same } \\
\text { impact, there can be several lines "I" for the same impact } \\
\text { (e.g. a MA studying the effect of organic farming on N2O } \\
\text { and CO2 emissions will be summarized by } 1 \text { "G" line for } \\
\text { the impact "GHG emission" and by } 2 \text { "I" lines for the each } \\
\text { reported metric - N2O emissions and CO2 emissions) }\end{array}$ \\
\hline & Authors & List of authors of the MA \\
\hline & Year & Publication year \\
\hline & Title & Publication title \\
\hline & Reference & $\begin{array}{l}\text { Publication reference (journal, volume, issue, start page, } \\
\text { end page). Only reported if InfoType = "G" }\end{array}$ \\
\hline & Type & $\begin{array}{l}\text { Publication type (whether the paper is a meta-analysis } \\
\text { (MA) or a non-quantitative systematic review (SR)). Only } \\
\text { reported if InfoType = "G" }\end{array}$ \\
\hline & Background & $\begin{array}{l}\text { Brief explanation of the scientific and societal background } \\
\text { of the MA. Only reported if InfoType = "G" }\end{array}$ \\
\hline & Objective & $\begin{array}{l}\text { Objective(s) of the MA. Several objectives can be reported } \\
\text { if the MA covers several impacts. All the objectives are } \\
\text { reported but the objective(s) related to reported results is } \\
\text { specified. Only reported if InfoType = "G" }\end{array}$ \\
\hline & Search_strategy & $\begin{array}{l}\text { Literature search strategy (searched databases, date of } \\
\text { the search and search equation and keywords). Only } \\
\text { reported if InfoType = "G" }\end{array}$ \\
\hline & Selection_criteria & $\begin{array}{l}\text { List of the criteria used by the authors to select the } \\
\text { individual studies included in the MA. Only reported if } \\
\text { InfoType = "G" }\end{array}$ \\
\hline & Data_analysis & $\begin{array}{l}\text { Statistical methods used by the authors to analyze the } \\
\text { data. Only reported if InfoType = "G" }\end{array}$ \\
\hline & Scale & $\begin{array}{l}\text { List continents or countries covered by the individual } \\
\text { studies, specifying the presence or not of Europe (the } \\
\text { target area). Only reported if InfoType = "G" }\end{array}$ \\
\hline & Data_in_Europe & $\begin{array}{l}\text { Mark whether the MA includes individual studies } \\
\text { conducted in Europe. Only reported if InfoType = "G" }\end{array}$ \\
\hline \multirow{4}{*}{$\begin{array}{l}\text { FULL TEXT ANALYSIS AND } \\
\text { EXTRACTED DATA: Study } \\
\text { quality rating. Only } \\
\text { reported if InfoType = } \\
\text { "G". }\end{array}$} & Number_of_papers & Number of individual studies included in the MA \\
\hline & List_of_studies & $\begin{array}{l}\text { References of individual studies could be listed in a table } \\
\text { or in a specific section }\end{array}$ \\
\hline & SelectionCriteria & Criteria used for selecting and discarding the studies \\
\hline & Objective_of_the_meta-analysis_specified & $\begin{array}{l}\text { The objective should be clearly specified in one sentence } \\
\text { or paragraph }\end{array}$ \\
\hline
\end{tabular}




\begin{tabular}{|c|c|c|}
\hline & Search_databases & Databases used for the literature search \\
\hline & Search_string & String including keywords used for the literature search \\
\hline & Number_of_studies_at_each_step & $\begin{array}{l}\text { Studies discarded at each step (at least, screening based } \\
\text { on titles and abstracts and full text analysis) }\end{array}$ \\
\hline & Quantitative_results_described & At least a mean effect size is presented \\
\hline & Statistical_methods_described & $\begin{array}{l}\text { Statistical methods used to estimate the mean effect } \\
\text { sizes, compute the confidence intervals etc. }\end{array}$ \\
\hline & Individual_effect_sizes & They could be presented in a figure, a table, an appendix \\
\hline & Individual_studies_weighted & $\begin{array}{l}\text { Weights are usually based on standard deviations and } \\
\text { sample sizes }\end{array}$ \\
\hline & Dataset_available & $\begin{array}{l}\text { The dataset can be made available in an appendix or a } \\
\text { repository }\end{array}$ \\
\hline & Confidence_intervals & At least for the mean effect sizes \\
\hline & Method_of_data_extraction & $\begin{array}{l}\text { Methods used to extract the data from the selected } \\
\text { papers (e.g., from the figures) }\end{array}$ \\
\hline & Heterogeneity_of_results_analyzed & $\begin{array}{l}\text { It can be based on a Q statistical test, on meta-regression, } \\
\text { on group-by-group meta-analysis }\end{array}$ \\
\hline & Funding_sources_mentioned & $\begin{array}{l}\text { Listing of funding sources contribute to the transparency } \\
\text { of the research work }\end{array}$ \\
\hline & Publication_bias_analyzed & $\begin{array}{l}\text { It can be based on funnel plot, trim and fill or on other } \\
\text { techniques }\end{array}$ \\
\hline & Quality_score_(\%) & $\begin{array}{l}\text { Quality score of the MA. Corresponds to the percentage } \\
\text { of quality criteria met by the MA }\end{array}$ \\
\hline $\begin{array}{l}\text { FULL TEXT ANALYSIS AND } \\
\text { EXTRACTED DATA: Study } \\
\text { results }\end{array}$ & $\begin{array}{l}\text { Result_1, Result_2, Result_3, Result_4 and } \\
\text { Result_5 }\end{array}$ & $\begin{array}{l}\text { Focus on the role of farming practice on a specific impact } \\
\text { (e.g. on soil fertility, but not on SOC or yield). If the MA } \\
\text { reports results for several outcomes, these results are } \\
\text { reported in separate lines. Only reported if InfoType = "G" }\end{array}$ \\
\hline & General_conclusion & $\begin{array}{l}\text { Main conclusion on the effect of the considered farming } \\
\text { practice on the outcome of interest. Only reported if } \\
\text { InfoType = "G" }\end{array}$ \\
\hline & $\begin{array}{l}\text { Factor1_Title, Factor2_Title, Factor3_Title, } \\
\text { Factor4_Title and Factor5_Title }\end{array}$ & $\begin{array}{l}\text { Factors (environmental characteristic or farming practice) } \\
\text { influencing the magnitude of the effect size. Only } \\
\text { reported if InfoType = "G" }\end{array}$ \\
\hline & $\begin{array}{l}\text { Factor1_direction, Factor2_direction, } \\
\text { Factor3_direction, Factor4_direction and } \\
\text { Factor5_direction }\end{array}$ & $\begin{array}{l}\text { Brief explanation of the direction of the influence of each } \\
\text { reported factor when the factor is a continuous variable, } \\
\text { or the results for the significant results for the different } \\
\text { levels of categorical variables. Only reported if InfoType = } \\
\text { "G" }\end{array}$ \\
\hline & Knowledge_gaps & $\begin{array}{l}\text { Major issues not covered by the MA highlighted by the } \\
\text { authors. Only reported if InfoType = "G" }\end{array}$ \\
\hline & Population & $\begin{array}{l}\text { Most important characteristics (type of crop or crop } \\
\text { systems) of the community in the pool of individual } \\
\text { studies included in the MA }\end{array}$ \\
\hline & Intervention & Tested farming practice or experimental treatment group \\
\hline & Intervention_matrix & $\begin{array}{l}\text { Similar to Intervention column, but homogeneized for } \\
\text { matrix computation. Only reported if InfoType = "I" }\end{array}$ \\
\hline & Control & Reference farming practice or experimental control group \\
\hline
\end{tabular}




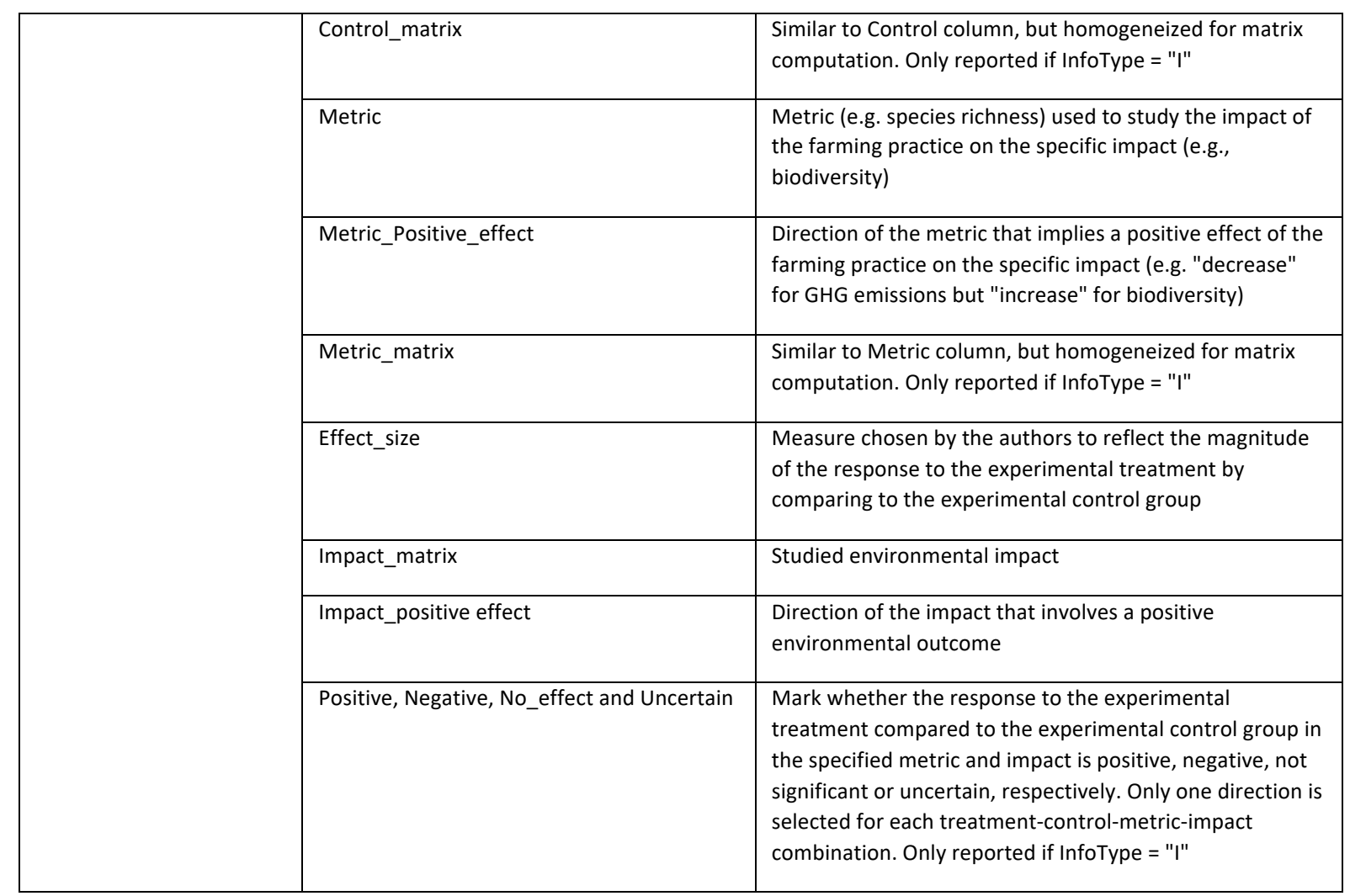


Appendix 2: One example of individual report generated for the farming practices "Nitrification inhibitor application". This report summarizes one of the meta-analyses assessing the impacts of this practice on crop yield and biomass. Similar fiches were generated for 16 MAs.

\author{
Nitrification inhibitors and yield \\ Reference 14 \\ Yang, M; Fang, YT; Sun, D; Shi, YL 2016 Efficiency of two nitrification inhibitors (dicyandiamide and 3, 4-dimethypyrazole phosphate) on soil \\ nitrogen transformations and plant productivity: a meta-analysis. Scientific Reports, 6 doi: 10.1038/srep22075

\section{Background and objective}

Nitrification inhibitors (NI) have been developed to mitigate nitrogen (N) losses through blocking the first stage of nitrification. Among the NI commercially available, dicyandiamide (DCD) and 3, 4-dimethypyrazol performances across field sites is less clear. In this study, using a meta-analysis approach, authors compared the efficiency of DCD and DMPP on altering plant productivity under various conditions including soil pH values, fertilizer $\mathrm{N}$ forms, fertilizer $\mathrm{N}$ rates and crop types.

\title{
Search strategy and selection criteria
}

Data were acquired by searching existing literature published before June 2015 using the ISI-Web of Science and Google Scholar. The following key words were used for searching such as meta-analysis, efficiency, nitrification inhibitor, DCD, DMPP, inorganic N, N leaching, gaseous emission and plant productivity. And the search terms were complemented with a search through the literature cited in the articles found 1)Field studies were selected and laboratory incubation studies were excluded, 2) at least one of the selected variables were measured; 3 ) means and sample sizes had to be reported; 4) treatment replicates were at least of three, etc.

Data and analysis

The mean effect sizes were estimated using the formulas described by Bai et al. (2013) and are weighed (for each study, the weighting factor was calculated as the inverse of the pooled variance, then adjusted by the total number of observations per site, when multiple observation for calculation of grouped effect sizes Confidence intervals (CIs) on the weighted effect size were generated using bootstraping (9g9g iterations).

Number
of

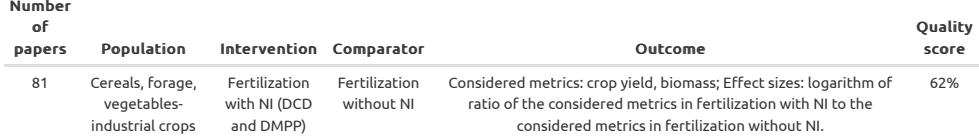

\section{Results}

- DCD significantly increased crop yield by $6.5 \%$, while DMPP did not (increased by $1.2 \%$; Cl: $-1.6 \%$ to $5.8 \%$ ).

- The efficiency of two $\mathrm{NI}$ differed in soil with different pH values. DMPP significantly increased crop yield by $9.4 \%$ (Cl: $2.0 \%$ to $11.2 \%$ ) only in alkaline soil, whereas DCD was both effective in acid and alkaline sol.

- DCD was effective along with organic fertilizer or urea, but DMPP did not significantly increase crop yield along with various $\mathrm{N}$ forms.

- DCD was effective in treatments of medium and high fertilizer $\mathrm{N}$ rates. DMPP did not have significant effect on crop yield under different fertilizer $\mathrm{N}$ rates treatments.

- Nl application
from Fig1).

Factors influencing effect sizes

Soil pH: higher impact in alkaline soils. N forms (for DCD): higher impact when applied with organic fertilizer or urea. $\mathrm{N}$ application rates (for DCD): higher impact in medium to high application rates. Crop type: no impact on cereals yields, but significant increase of vegetables and forage crop yields.

\section{Conclusion}

In average, DCD application significantly increased crop yield and biomass, while DMPP application significantly increased biomass (no significant effect of DMPP application on crop yield). 


\section{Appendix 3: General report produced for the farming practice "Nitrification inhibitor application" based on 16 meta-analyses.}

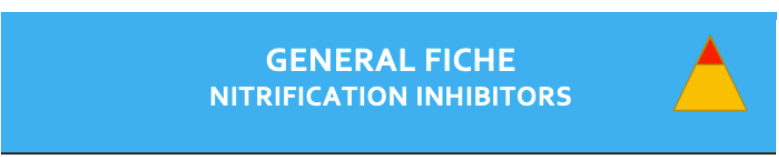

Data extracted in October 2020

Note to the reader: This general fiche summarises all the environmental and climate impacts of the application of Note to the reader: This
NITRIFICATION INHIBIT NITRIFICATION INHBBITORS
16 synthesis research papers?

The general fiche provides the highest level of synthesis - symbolised by the top of the pyramid $\Delta$. As each synthesis research paper involves a number of individual papers ranging from 4 to 376 , the assessment of impacts relies on a large number of results obtained mainly in field experiments (carried out in situations close to rea farming envirnment), and sometimes in lab experments or rom model simulations. In addition to this general pollutants emissions, crop yield, greenhouse gas (GHG) emissions, nitrogen retention in soil, nitrogen Telling leaching/runoff and plant nitrogen-uptake), with more detailed information - medium part of the pyramid Finally, individual reports provide full information about the results reported in each synthesis paper, in particular A.

This general fiche on nitrification inhibitors is part of a set of similar fiches providing a comprehensive picture of the impacts of farming practices on climate and environment.

1. DESCRIPTION OFTHE FARMING PRACTICE

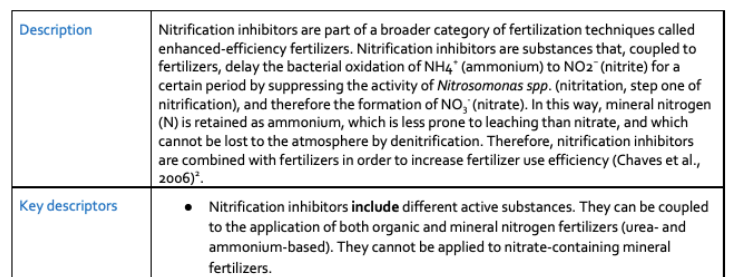

${ }^{2}$ Research synthesis papers include a formal meta-analysis (MA) or systematic reviews (SR) with some quantitative results.

"Chaves, B., Opoku, A., De Neve, S., Boeckx, P., Van Cleemput, O., \& Hofman, G. (2006). Influence of DCD and
DMPP on soil N dynamics after incorporation of vegetable crop residues. Biology and Fertility of Soils, $43(1)$, 62 .

3. DESCRIPTION OF THE KEY FACTORS INFLUENCING THE SIZE OFTHE EFFEC Only the factors explicitly studied in the reviewed synthesis papers are reported below. Details regarding the factors can be found in the individual reports following the hyperlinks (匹or refy).

\begin{tabular}{|c|c|}
\hline IMPACTS & FACTORS \\
\hline \begin{tabular}{|l|} 
Decrease of air pollutants emission \\
$\left(\mathrm{NH}_{3}, \mathrm{NO}\right)$
\end{tabular} & 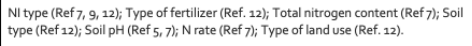 \\
\hline $\begin{array}{l}\text { Decrease } \mathrm{GHG}_{\mathrm{H}} \text { emission }\left(\mathrm{N}_{2} \mathrm{O} \text {, }\right. \\
\left.\mathrm{CH}_{4}, \mathrm{CO}_{2}\right)\end{array}$ & 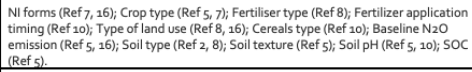 \\
\hline \begin{tabular}{|l} 
Decrease of $\mathrm{N}$-leaching or runoff \\
$\left(\mathrm{NO}_{3} ; \mathrm{NH}_{4}+\mathrm{DIN} *\right)$
\end{tabular} & \begin{tabular}{|l} 
SOC content (Ref 7); Fertilizer type (Ref 12); N forms (Ref 11); N application rate \\
(Ref 7, 12); Soil texture (Ref 12); Type of land use (Ref 122).
\end{tabular} \\
\hline Increase plant N-uptake & 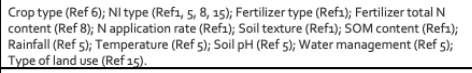 \\
\hline \begin{tabular}{|l|} 
Increase soil retention of fertilizer- \\
derived N forms ( $\mathrm{NH}_{4}+\mathrm{NO}_{3}$; All \\
N-forms
\end{tabular} & 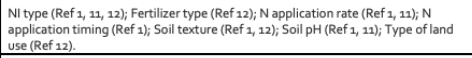 \\
\hline Increase yield & 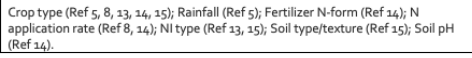 \\
\hline
\end{tabular}

4. IMPLEMENTATION IN THE PERIOD 2014-2020

\begin{tabular}{|l|l|}
\hline $\begin{array}{l}\text { GAEC Cross } \\
\text { compliance }\end{array}$ & \\
\hline Greening & \\
\hline $\begin{array}{l}\text { Rural } \\
\text { development } \\
\text { measure- } \\
\text { submeasure }\end{array}$ & \\
\hline
\end{tabular}

5. PICTURES

Pictures are not relevant in this case.

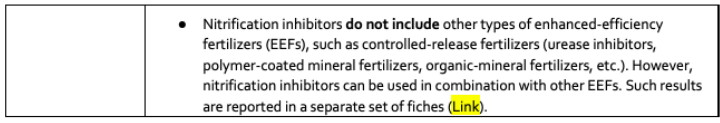

2. DESCRIPTION OF THE IMPACTS OF THE FARMING PRACTICE ON ENVIRONMENT AND CLIMATE

We consider the impacts of nitrogen-fertilization coupled to nitrification inhibitors (NI), as compared to nitrogen-fertilization without $\mathrm{N}$.

In the Table below, the numbers indicate the number of synthesis papers reporting the effect. For each impact, the effect with the higher score is marked in bold and the cell coloured. The numbers between parenthesis indicate he number of synthesis papers with a quality score higher than or equal to $50 \%$. Details on quality criteria can be found in this document $z$.

Out of 16 synthesis papers ${ }^{2}, 6$ included studies conducted in Europe and 14 have a quality score higher than $50 \%$ Some synthesis papers reported more than one impact.

\begin{tabular}{|c|c|c|c|c|c|}
\hline \multicolumn{2}{|l|}{ Impact } & Positive & Negative & No effect & Uncertain \\
\hline \multirow[t]{2}{*}{ Decrease of air pollutants emission } & $\mathrm{NH}_{3}$ & o & 5(5) & 5(5) & $1(0)$ \\
\hline & NO & 3(3) & $\circ$ & 1(1) & $\circ$ \\
\hline \multirow[t]{3}{*}{ Decrease of GHG emission } & $\mathrm{N}_{2} \mathrm{O}$ & 9(8) & $\circ$ & $\circ$ & 1(0) \\
\hline & $\mathrm{CH}_{4}$ & 1(1) & 0 & $2(2)$ & o \\
\hline & $\mathrm{CO}_{2}$ & 1(1) & $\circ$ & 1(1) & $\circ$ \\
\hline \multicolumn{2}{|l|}{$\begin{array}{l}\text { Decrease of } \mathrm{N} \text { leaching or run-off } \\
\left(\mathrm{NO}_{3} ; \mathrm{NH}_{4}, \mathrm{DiN} *\right)\end{array}$} & $4(4)$ & $2(2)$ & 1(1) & $\circ$ \\
\hline \multicolumn{2}{|l|}{ Increase plant $\mathrm{N}$-uptake } & $5(5)$ & $\circ$ & 4(4) & o \\
\hline \multirow[t]{3}{*}{ Increase soil content of fertilizer-derived $\mathrm{N}$ forms } & $\mathrm{NH}_{4}^{+}$ & $2(2)$ & $\circ$ & $\circ$ & $\circ$ \\
\hline & $\mathrm{NO}_{3}$ & $\circ$ & $2(2)$ & $\circ$ & $\circ$ \\
\hline & $\begin{array}{l}\text { All } \mathrm{N} \\
\text { forms* }\end{array}$ & 1(1) & $\circ$ & 2(2) & $\circ$ \\
\hline \multicolumn{2}{|l|}{ Increase yield } & $6(6)$ & $\circ$ & 3(3) & $\circ$ \\
\hline
\end{tabular}

*All introgen (N) forms include dissolved inorganic nitrogen forms $\left(\mathrm{NH}_{4}\right.$; $\mathrm{NO}_{3}$; $\mathrm{NO}_{2}$ ) and organic $\mathrm{N}$.
We include in this section the links to other complementary sources of information (not peer-reviewed metaanalyses or systematic reviews), provided by AGRI or other stakeholders.

7. LIST OF SYNTHESIS PAPERS INCLUDED IN THE REVIEW OF THE FARMING PRACTICEIMPACTS

\begin{tabular}{|c|c|c|c|c|c|}
\hline & Authors & Year & Article Title & Source Tith & DOI \\
\hline & 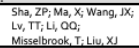 & & 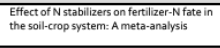 & $\begin{array}{l}\text { Agriculture, Ecosystems and } \\
\text { Environment, 290, 106763 }\end{array}$ & 10.10166j.agee.2019.106763 \\
\hline & 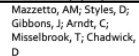 & & 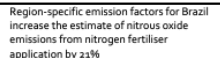 & $\begin{array}{l}\text { Atmosphencic Environments } \\
230,27566\end{array}$ & 10.1016 \\
\hline & 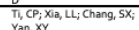 & 2019 & 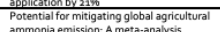 & Environmental Pollution, & 10.10066j:envpol.2018.10.124 \\
\hline & $\begin{array}{l}\mathrm{Yan}, \mathrm{Xr}, \mathrm{Man}, \mathrm{XM} \\
\mathrm{Ga}, \mathrm{WL} ; \mathrm{M}\end{array}$ & 2017 & 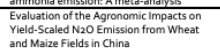 & 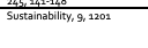 & 10.3390//1090/1201 \\
\hline 5 & 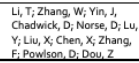 & & 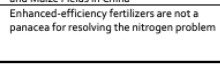 & $\begin{array}{l}\text { Glob Change Biol. } \\
2008 ; 24 \text { est12-522. }\end{array}$ & 10.1121/gcb. 39918 \\
\hline & 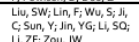 & 2017 & $\begin{array}{l}\text { A meta-analysis of fertilizer-induced soil } \\
\text { No and combined } N \mathrm{O}+\mathrm{N} 2 \mathrm{~N} 2 \mathrm{O} \text { emissions }\end{array}$ & 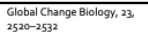 & 10.1121/gcb.13485 \\
\hline & 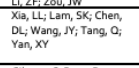 & 2017 & 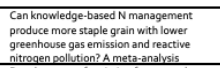 & $\begin{array}{l}\text { Global Change Bilology, 23. } \\
\text { 1927-1925 }\end{array}$ & $10.11121 / \mathrm{gcb} .13455$ \\
\hline & 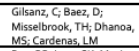 & & 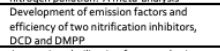 & $\begin{array}{l}\text { Agriculture, Ecosystem \& } \\
\text { Environment, } 226,1,-8\end{array}$ & 10.10166j].agee. 2015 .09. \\
\hline & $\begin{array}{l}\text { Pan, BB; Lam, SK; Mosi } \\
\text { A; Luo, YQ; Chen, DL }\end{array}$ & & 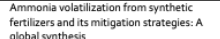 & $\begin{array}{l}\text { Agninulture, Ecosystems and } \\
\text { Environment, } 232,283-289\end{array}$ & 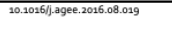 \\
\hline 10 & 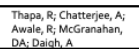 & 2016 & 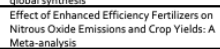 & $\begin{array}{l}\text { Soli Ici. Soc. Am.1. 80: 12121- } \\
\text { 1134 }\end{array}$ & 10.2136/15ss]2016.06.0179 \\
\hline 13 & 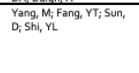 & 2016 & 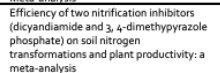 & Scientific Reports, 6 & 10.1038/sep 22075 \\
\hline$\overline{12}$ & 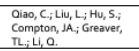 & 2015 & 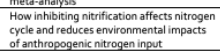 & 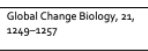 & $10.1111 / 9 \mathrm{gcb} .12802$ \\
\hline 13 & 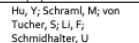 & 2013 & 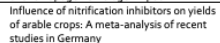 & $\begin{array}{l}\text { Interantional Journal of } \mathrm{P} \\
\text { Production } 8(12,33-50\end{array}$ & $12069 / \mathrm{IPP}$ \\
\hline$\overline{14}$ & $\begin{array}{l}\text { Kim, DG; Saggar, S; } \\
\text { Roudier, } P\end{array}$ & 2012 & 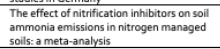 & groecosyst 93:51- & $10.1007 /$ s150705-0212-9498-9 \\
\hline 15 & 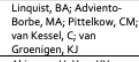 & & 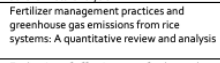 & $\begin{array}{l}\text { Field crops Research, } 235 \text {. } \\
\text { 20-22 }\end{array}$ & 10.10066j:ftr.2012.06..007 \\
\hline & & & 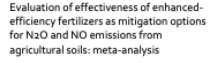 & & \\
\hline
\end{tabular}

6. LINKS TO OTHER RELEVANT COMPLEMENTARY INFORMATION 
Appendix 4: Example of a single-impact report produced for the farming practice "Nitrification inhibitor application". Similar reports were produced for other impacts shown in appendix 3.

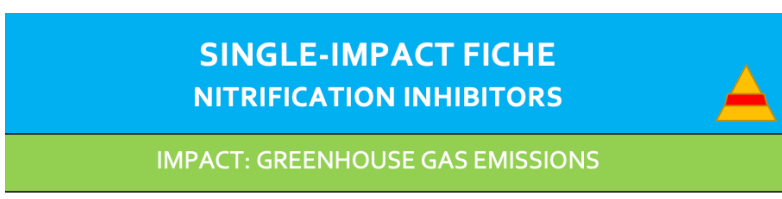

Data extracted in October 202

Note to the reader: This fiche summarises the impact of the application of nitrification inhibitors (NI) in nitrogen fertilization practices (both mineral and organic) on GREENHOUSE GAS (GHG) EMISSIONS. It is based on 10 peerreviewed synthesis research papers $5^{2}$, each of them including from 10 to 376 individual studies.

1.WEIGHT OF THE EVIDENCE

CONSISTENCY OF THE IMPACT: The effect on GHG emissions was reported for carbon dioxide $\left(\mathrm{CO}_{2}\right)$ $\mathrm{N}_{2} \mathrm{O}$ emissions) by the application of different types of $\mathrm{N} / \mathrm{in}$ combination with different $\mathrm{N}$-fertilizers (either mineral or organic) ( able 1). However, the application of $\mathrm{N}_{\text {sh }}$. $\mathrm{MA}$, peports $\mathrm{n}$ effect of the $\mathrm{NI}$ dicrandiamide $(\mathrm{DCD})$ and one a positive effect of the $\mathrm{N}$, 34 dimethylpyrazole phosphate (DMPP)

Out of 10 synthesis papers, five reported studies conducted at global scale (including EU), four outside the $\mathrm{EU}$, and one did not specify the scale.

Table 1. Summary of effects. The effect with the higher score is marked in bold and the cell coloured. The numbers betwe can be found in the next section.

\begin{tabular}{|c|c|c|c|c|c|}
\hline \multicolumn{2}{|c|}{ Impact } & Positive & Negative & No effect & Uncertain \\
\hline \multirow{4}{*}{ Decrease of GHG emissions } & $\mathrm{N}_{2} \mathrm{O}$ & $9(8)$ & 0 & 0 & $1(0)$ \\
\cline { 2 - 7 } & $\mathrm{CH}_{4}$ & $1(1)$ & 0 & $2(2)$ & 0 \\
\cline { 2 - 7 } & $\mathrm{CO}_{2}$ & $1(1)$ & 0 & $1(1)$ & 0 \\
\hline
\end{tabular}

- QUALITY OF THE SYNTHESIS PAPERS: The quality score summarises 16 criteria assessing the quality of three main aspects of the synthesis papers: 1) the literature search strategy and studies selection; 2) the
statistical analysis; 3 ) the potential bias. Details on quality criteria can be found in this document $\geq$. methane $\left(\mathrm{CH}_{4}\right)$ and nitrous oxide $\left(\mathrm{N}_{2} \mathrm{O}\right)$. Nine synthesis papers' show a robust positive effect (decrease of missions. For $\mathrm{CH}$ (COnsidering bo the decrease of direct emissions and the removal from the

As shown in the "Quality score" column of the table in section 2, the quality level ranges from $38 \%$ to $69 \%$. The least satisfied quality criteriawere "Search string", Number of studies at each step", "Individual effect

2. IMPACTS

The main characteristics and results of the synthesis papers are summarized in Table 2. Detailed results of each synthesis study are reported in the summary reports

Table 2. Main characteristics of the synthesis papers reporting impacts on $\mathrm{GHG}$ emission. The references are ordered

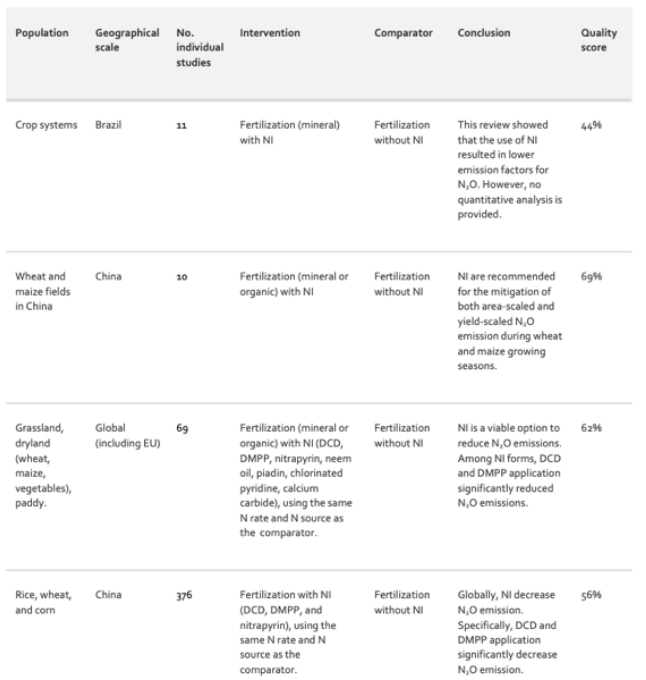

Research synthesis papers include a formal meta-analysis (MA) or systematic reviews (SR) with some quantit

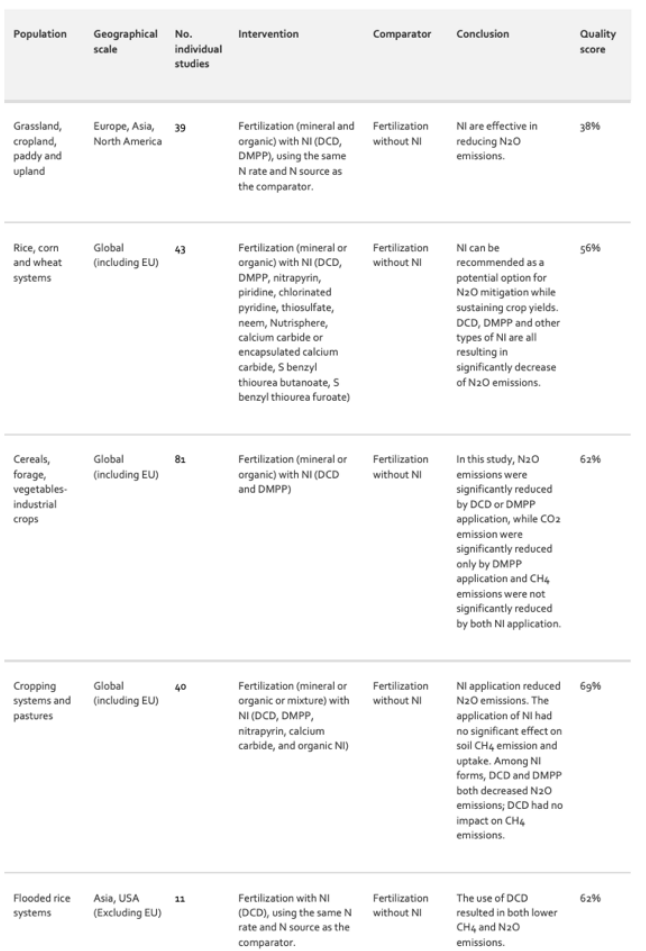

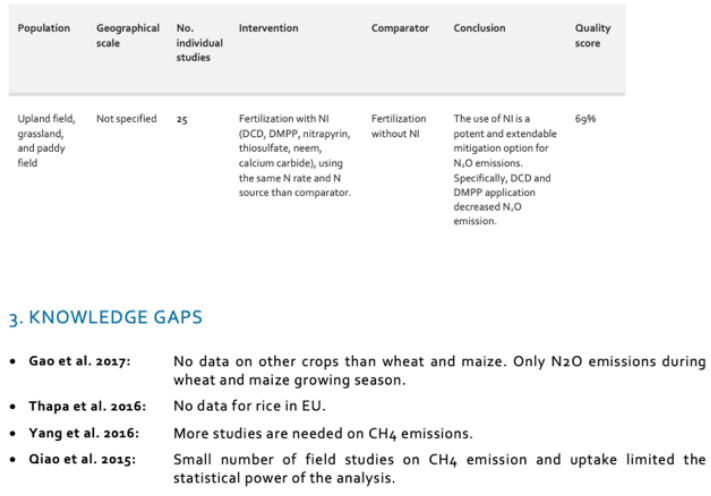

4. SYSTEMATIC REVIEW SEARCH STRATEGY

\begin{tabular}{|l|l|}
\hline Keywords & $\begin{array}{l}\text { TOPIC: ("nitr* inhibitt" OR "controlled-release fert*" OR "urease inhibitt" OR "enhanced- } \\
\text { efficiency fert*") AND TOPIC: ("meta-analy*" OR "systematick review*" OR "evidence map" OR } \\
\text { "global synthesis" OR "evidence synthesis" OR "research synthesis") }\end{array}$ \\
\hline Search dates & No time restrictions \\
\hline Databases & Web of Science and Scopus, run on 6 October 2020 \\
\hline $\begin{array}{l}\text { Selection } \\
\text { criteria }\end{array}$ & $\begin{array}{l}\text { Three main criteria led to the exclusion of a synthesis paper: (1) the paper does not deal with } \\
\text { nitrification inhibitors; (2) the paper does not assess the impacts of fertilization using nitrification } \\
\text { inhibitors in comparison to another fertilization technique; (3) the paper is neither a meta-analysis } \\
\text { nor a systematic ceview. Synthesis papers that passed the relevance criteria were subject to critical } \\
\text { appraisal carried out on paper-by-paper basis. From an initial number of } 55 \text { synthesis papers, we } \\
\text { finally selected 10 meta-analysis. }\end{array}$ \\
\hline
\end{tabular}

